\title{
Pharmacy Workload and Workforce Requirements at MOH Primary Health Care Center during Ten years Mass Gathering Hajj (2006-2015) in Makah Region, Saudi Arabia
}

\author{
Yousef Ahmed Alomi*1, Khairat Alhennawi ${ }^{2}$, Nizar Khayayt ${ }^{3}$ \\ ${ }^{1}$ The Past General Manager of General Administration of Pharmaceutical Care and \\ Head, National Clinical pharmacy, and pharmacy practice and Pharmacy R and D Administration, \\ Ministry of Health, Riyadh, KSA \\ ${ }^{2}$ Clinical pharmacy staff, General Administration of Pharmaceutical Care, Ministry of Health, Riyadh, KSA \\ ${ }^{3}$ Medication Safety Officer General Administration of Pharmaceutical care, Makkah Region, \\ Ministry of Health, Riyadh, KSA
}

Received: 13 August 2017;
Accepted: 28 September 2017
*Correspondence to:
Dr. Yousef Ahmed Alomi,

The Past General Manager of General Administration of Pharmaceutical Care, Head, National Clinical pharmacy, and pharmacy practice, Head, Pharmacy R and D Administration, Ministry of Health, P.O.BOX 100, Riyadh 11392, Riyadh, Saudi Arabia. Email:yalomi@gmail.com

Copyright: (C) the author(s),publisher and licensee Indian Academy of Pharmacists. This is an openaccess article distributed under the terms of the Creative Commons Attribution Non-Commercial License, which permits unrestricted non-commercial use, distribution, and reproduction in any medium, provided the original work is properly cited.

\begin{abstract}
Purpose: To explore the pharmaceutical care workload analysis and workforce requirements at Ministry of Health Primary health care centers during mass gathering Hajj ten years (20062015), Saudi Arabia. Methods: It is a retrospective study of ten years (2006-2015) in primary health care center (PCC) about pharmacies workload during mass gathering Hajj period. The duration of workload collection was 15 days. The pharmacist and pharmacy technicians provide pharmaceutical care to all patients either Pilgrim or not Pilgrim at Makah region. It included Mona holy places hospitals; Arafat holy places hospitals, and Makah city. The workforce requirements calculated based on $\mathrm{MOH}$ workforce standards of primary health care center and the workload drives as central pharmacy services, patient specific pharmacy activities, and general administration specific pharmacy activities. Results: The total number of pilgrims $(1,952,817-$ $3,161,573)$ with average $(2,445,208)$. The average number PCC prescription at holy places were $(275,820)$ and $(138,388.4)$ from Makah city. The average number of pharmacist needed (24.92 FTE) per each PCC at holy places, and (27.97 FTE) per each PCC at Makah city. The average number of pharmacist based on $\mathrm{MOH}$ standards at Makkah region PCC was (678.50 FTE) while the mean number pharmacist needed based on workload was (3,451.72 FTE) at Makkah region. It is $(5.17$ fold) more incremental than $\mathrm{MOH}$ pharmacist workforce standards. Conclusion: The pharmacy workload analysis at primary health care center reflected the real demand for pharmacists. Clinical pharmacy activities at PCC missed with emphasis on patient-specific clinical pharmacy. Targeting to change pharmacy workforces improves pharmacy services provided to all pilgrims in Makkah region, Saudi Arabia.

Key word: Pharmaceutical Care, Workload, Workforces, Primary Care Center, Mass Gathering, Hajj, Makkah.
\end{abstract}

\section{INTRODUCTION}

Hajj is an annual religious gathering (Islamic pilgrimage) that occurs every year in Makah, Saudi Arabia. Attracting more than 2 million Muslims annually, making it one of the most significant mass gatherings in the world. It is a great example that 
could be studied by researchers (especially because of its repetitiveness every year) to assess the needs for such events to help to organize and improving services in all mass gathering that may occur. ${ }^{[1]}$ Some health problems may take place during Hajj because of crowding, heat, behavior and general health of peoples. So that, World Health Organization and other authorities pay special attention to these gatherings and developing guidelines, especially for controlling communicable diseases due to their risk for individuals and their home countries when they return. However, all types of diseases are common during Hajj or other mass gatherings, and they are not limited to communicable (infectious) diseases as several studies declared it..$^{[2-4]}$

Despite the type of illness and the individual's health, almost all patients require one of the important aspects of health care system, the pharmaceutical care. The interventions of clinical pharmacists in mass gathering medicine are of paramount importance that not adequately discussed in the literature. Several studies were done to assess mass gathering medicine, the patterns of diseases, and vaccination effectiveness during hajj, but Alomi et al., the first studied the national mass gathering pharmaceutical care in Saudi Arabia in 2016. ${ }^{[4-8]}$ After very extensive literature review and only limited number of studies discussed utilized physician and nurses during mass gathering events but not pharmacists with the emphasis of primary care centers. ${ }^{[9-11]}$ Most of the patients during hajj prefer primary health care centers to hospitals because they are of higher abundance and easier to reach. Also, the patients during hajj prefer fast services due to their tight schedule. The author not familiar with published studies discussed primary care center pharmacy workforces during mass gathering meeting or even during Haji period in Saudi Arabia or Gulf countries and the Middle East countries. In addition to worldwide countries. Because of that, the authors have concentrated on our study on pharmaceutical care during mass gathering; Haji, and the workload and workforce requirements of pharmacists during this period in Makkah region primary health care centers in particular.

\section{METHODS}

It is a retrospective analysis of ten years (2006-2015) of primary healthcare center (PCC) pharmacies workload during mass gathering Hajj period. The duration of workload collection was 15 days. The primary healthcare is the first and the easiest level the patient could reach if they have any health problem. All the data derived from Ministry of Health. Health Statistical Year Books. ${ }^{[12-21]}$ At primary healthcare centers, the patient will receive safe and fast health services such as; medical examination, some blood analysis, and patient follow-up. The patients also will receive their medications with proper counseling and education. ${ }^{[2]}$ There are about 158 primary care centers in Makah region; 46 in Makah city and 112 in holy places (Mina and Arafat). The pharmacist and pharmacy technicians provide pharmaceuticals to all patients (Pilgrim or not Pilgrim). The clinical pharmacist at primary care centers may work in; administrative affairs unit, total quality unit, medical supply unit, medication safety unit, clinical pharmacy unit, and pharmacy unit. The pharmacists there manage patients with acute and chronic common illnesses and provide sufficient care for patients who do not need a hospital. ${ }^{[22]}$ Also, there was extensive literature review search at open date periods with fifty databases. It included the type of studies (meta-analysis, randomized controlled studies, and observational studies, books, reports...etc) in the English language. The search for the term of Hajj and workforce, Hajj and workforce, Hajj and human resources or mass gathering and workforce, mass gathering and workforce, mass gathering and human resources. The search term was in the title and keywords. All setting of patient care services; hospitals inpatient or ambulatory care or community services included. The search included pharmacist and clinical pharmacist. Pharmacy technician excluded from the study. The location of studies included Saudi Arabia as top propriety if not existed Gulf or Middle East countries included, and if not found overall countries included. The workforce requirements calculated based on $\mathrm{MOH}$ workforce standards of primary health care center and the workload drives as central pharmacy services, patient-specific pharmacy activities, and general administration specific pharmacy activities. ${ }^{[23-26]}$ The workload calculation based on pharmacy administration database in Makkah region with considered that is an average time of pharmacist dispensing PCC prescription was 4 min and the mean number of medication per each prescription was three. All calculation done used Microsoft Excel version ten.

\section{RESULTS}

The total number of pilgrims was $(1,952,817-3,161,573)$ with average $(2,445,208)$. The total number of prescriptions $(226,824-505,753)$ with average $(411,317)$, it represented $(7.12-20.25 \%)$ with average $(16.77 \%)$ of all pilgrims. The number of primary care centers in Makah was $(36-46)$ with an average of (41.7), while in holy places there was $(80-112)$ with a mean of (4.9) Primary Care Centers as explored Table 1. The average number PCC prescription 


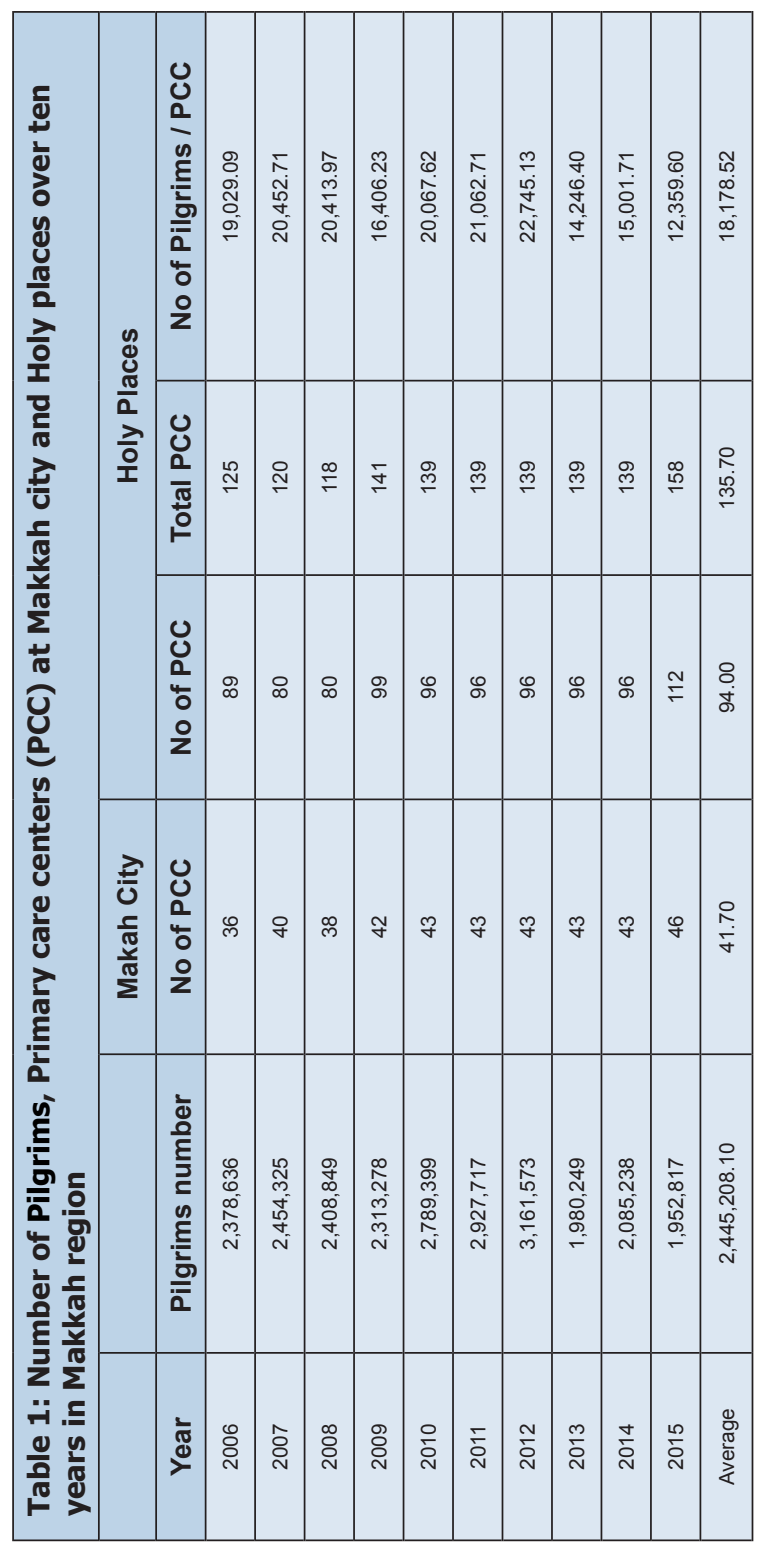

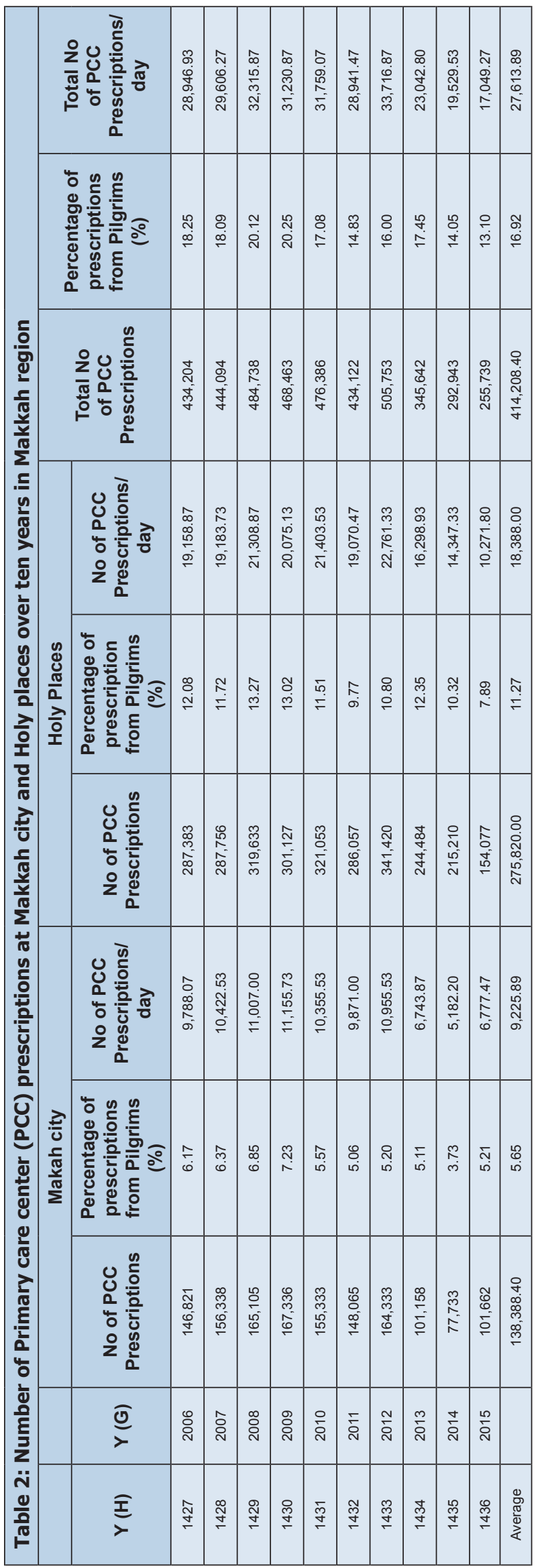


at holy places were $(275,820)$ and $(138,388.4)$ from Makah city. The average number of PCC order at sacred sites was $(9,225.89)$ per day and contained $(27,677.67)$ medications, while at PCC in Makah city was $(18,388)$ prescriptions per day and contained $(55,164)$ drugs as explored Table 2 . The average number of pharmacist needed (24.92 FTE) per each PCC at holy places, and (27.97 FTE) per each PCC at Makah city. The average number of pharmacist based on MOH standards at Makkah region PCC was (678.50 FTE) while the mean number pharmacist needed based on workload was (3,451.72 FTE) at Makkah region. It is (5.17 standards as explored Table 3 and Table 4. There were no any central pharmacy activities, and clinical pharmacy services or administrative pharmacy activities.

\section{DISCUSSION}

The primary healthcare services had developed and expanded several times in the ten years. ${ }^{[21]}$ The Ministry of Health established special part of primary care centers (PCCs) among healthcare strategic plan 2010-2020. ${ }^{[27]}$ The the pharmacy primary healthcare workforces in 2014 and established pharmacist primary healthcare competency for various specialties of primary care services. ${ }^{[3-22]}$ Also, they formulated primary healthcare committee with a membership of several primary care pharmacist from the different center in Riyadh city to implement several pharmacy practices and clinical pharmacy services. Also, the first publication of patient satisfaction of Pharmaceutical Care in a primary care center in Saudi Arabia and Middle East countries through the MOH pharmacy administration. ${ }^{[28]}$ Furthermore, pharmacy primary care skeleton updated and implemented in past years. It consisted of several units including Ambulatory care pharmacy, medication safety. Pharmacy total quality management, and drug information center. ${ }^{[23]}$ All previous successful plans covered all primary healthcare centers including Makkah city and holy places. The authors did the study to evaluate the new guidelines of workforces and compare with workload analysis by using dispensed prescriptions during mass gathering Hajj period. The number of PCCs has increased dramatically in the last years, if we look at the number of prescriptions in PCC through years, we will notice much decrease in the last years compares with the past. It may be due to the reduction in health problems during Hajj because of health awareness and vaccination. The findings showed the high demand of primary care pharmacist more than $\mathrm{MOH}$ standards with five times fold during mass gathering Hajj period if compared to study conducted in Saudi Arabia in fold) more incremental than $\mathrm{MOH}$ pharmacist workforce general administration of pharmaceutical care released

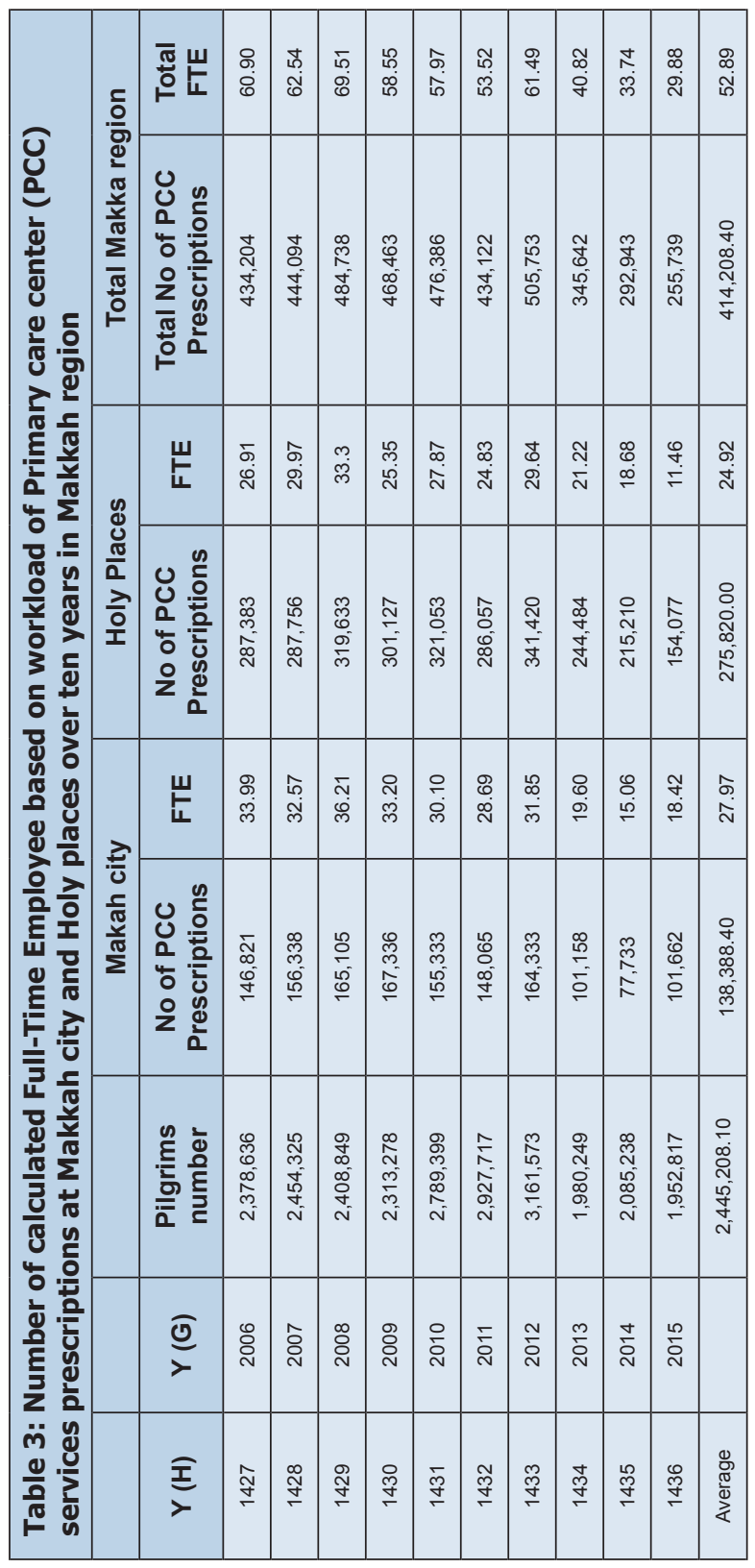




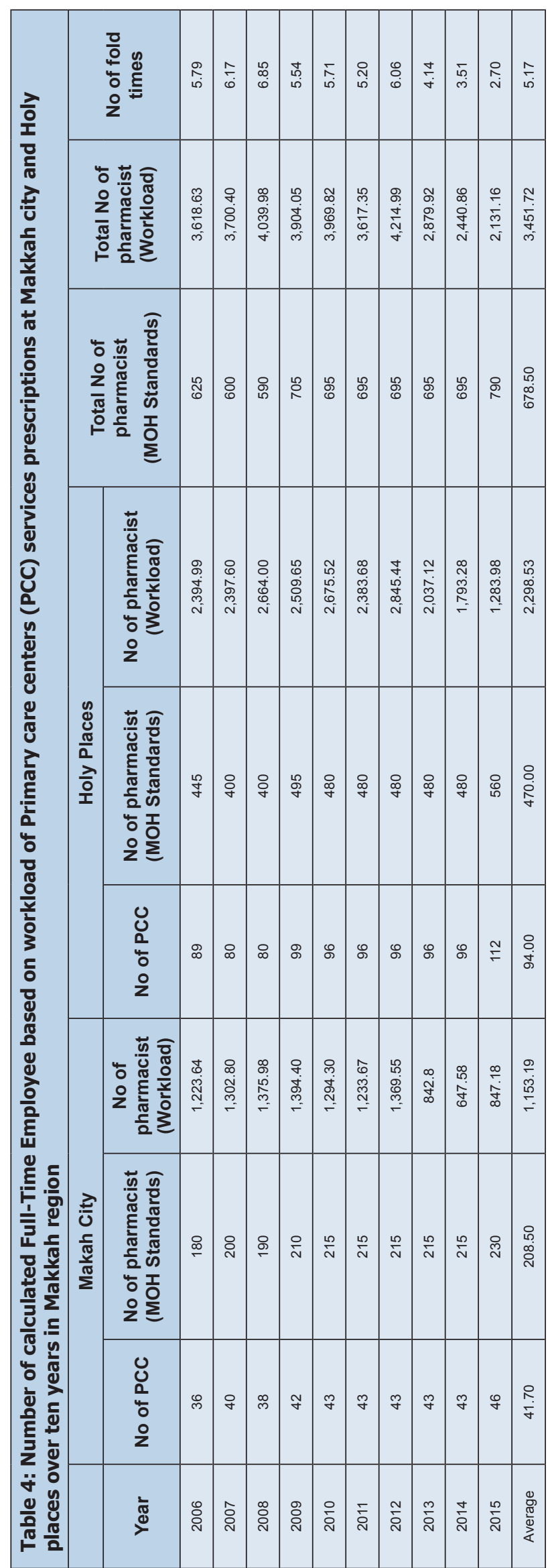

2014 that make the standards of the number of pharmacy staff in a primary care center. ${ }^{[23]}$ Another study shows that we need one pharmacist for each 10,000 population. ${ }^{\left[{ }^{[2]}\right.}$ The limitation of comparing the results of these studies was in the population; these studies were studying normal PCCs with a normal number of patients, despite our study, which studies PCCs in mass gathering event. There is no study in the overall the world study to compare with results. It seems to the first investigations about workforces of primary care pharmacist during mass gathering Haij period. These results reflect the real needs of pharmacists during Hajj period and the shortage present in pharmacy staff. The authors excluded the pharmacy technician and clinical pharmacist with another study in the future investigated.

\section{Limitation}

Despite the importance of the study, finding the study had several limitations and the author could not control them. The missing of official through $\mathrm{MOH}$ or general administration of pharmaceutical care the documentation of the number of pharmacist or pharmacist activities at PCC. Also, the number and type of medication dispensed through PCCs missed.

\section{CONCLUSION}

The primary health care centers had very high demanding of a pharmacist during mass gathering Hajj period in Makkah region, Saudi Arabia. Targeting to change $\mathrm{MOH}$ pharmacy workforces requirement by the increased number of pharmacist staff during mass gathering Hajj time, and an electronic documentation of prescriptions and pharmacy activities. That would reflect actual of pharmacy workforces and improve pharmaceutical care services offered to all pilgrims during mass gathering Hajj time visit Makkah region in Saudi Arabia.

\section{ACKNOWLEDGEMENT}

I want to thank all staff at Health affairs administration and pharmaceutical care administration in Makkah region for their cooperation.

\section{CONFLICT OF INTEREST}

None

\section{ABBREVIATION USED}

KSA: Kingdom of Saudi Arabia, MOH: Ministry of Health, 
PCC: Primary care center.

\section{REFERENCES}

1. World Health Organization. Public health for mass gathering: key considerations. 2015; Available from www.who.int/about/licensing/ copyright_form/en/index.html.

2. Steffen R, Bouchama A, Johansson A, Dvorak J, Isla N, Smallwood C, et al. Non-communicable health risks during mass gatherings. Lancet Infect Dis. 2012;12(2):142-9.

3. Memish ZA. The Hajj: communicable and non-communicable health hazards and current guidance for pilgrims. Euro Surveillance. 2010;15(39):19671.

4. Khan NA, Ishag AM, Ahmad MS, El-Sayed FM, Bachal ZA, Abbas TG. Pattern of medical diseases and determinants of prognosis of hospitalization during 2005 Muslim pilgrimage (Hajj) in a tertiary care hospital. A prospective cohort studies. Saudi Med J. 2006;27(9):1373-80.

5. Memish ZA, Stephens GM, Steffen R, Ahmed QA. Emergence of medicine for mass gatherings: Lessons from the Hajj. Lancet Infect Dis. 2012;12(1):56-65.

6. Al-Tawfiq JA, Memish ZA. Mass Gatherings and Infectious Diseases. Prevention, Detection, and Control. Infect Dis Clinics North Am. 2012;26(3):726-37.

7. Ahmed-Alomi $Y$, Pharm B, Clin-Pharm M. National Mass Gathering Pharmaceutical Care Program at $\mathrm{MOH}$ in Saudi Arabia. J Pharm Pract Community Med. 2016;2(23):102-3.

8. Sanders Ab, Criss E, Stecki P, Meislin HWH, Raife J, Allen, et al. An analysis of medical care at mass gatherings. Ann Emergency Med. 1986;15(5):515-9.

9. Smith WP, Wessels V, Naicker D, Leuenberger E, Fuhri P, Wallis LA, et al. Development of a mass-gathering medical resource matrix for a developing world scenario. Prehospital Disaster Med. 2010;25(6):547-52.

10. Centre for Excellence in Emergency Preparedness $\odot$ An Introduction to Mass Gatherings Introduction to Mass Gatherings. 2014. Available from http://www.ceep.ca/publications/Mass_Gatherings.pdf.

11. Alomi YA, Zahran R. Self-Assessment of mass gathering (Hajj) pharmaceutical care program in Saudi Arabia. J Pharm Practice Community Med. 2016;2(24):137-43.

12. Saudi Ministry of Health. Health Statistical Year Book 2006. Available from http://www.moh.gov.sa/en/Ministry/Statistics/book/flash/1427/ MOH_Report_1427.html.

13. Saudi Ministry of Health. Health Statistical Year Book 2007. Available from http://www.moh.gov.sa/en/Ministry/Statistics/book/flash/1428/ $\mathrm{MOH} \_$Report_1428.html.

14. Saudi Ministry of Health. Health Statistical Year Book 2008. Available from: http://www.moh.gov.sa/en/Ministry/Statistics/book/flash/1429/ MOH_Report_1429.html.

15. Saudi Ministry of Health. Health Statistical Year Book 2009. Available from http://www.moh.gov.sa/en/Ministry/Statistics/book/flash/1430/ MOH_Report_1430.html.

16. Saudi Ministry of Health. Health Statistical Year Book 2010. Available from http://www.moh.gov.sa/en/Ministry/Statistics/book/Pages/default.aspx.

17. Saudi Ministry of Health. Health Statistical Year Book 2011. Available from http://www.moh.gov.sa/en/Ministry/Statistics/book/Pages/default.aspx.

18. Health Statistical Year Book 2012. Saudi Ministry of Health. Available from: http://www.moh.gov.sa/Ministry/Statistics/book/Documents/1433.pdf.

19. Saudi Ministry of Health. Health Statistical Year Book 2013. Available from: http://www.moh.gov.sa/en/Ministry/Statistics/book/Pages/default.aspx.

20. Health Statistical Year Book 2014. Saudi ministry of Health. Available from: http://www.moh.gov.sa/en/Ministry/Statistics/book/Documents/StatisticalBook-for-the-Year-1435.pdf.

21. Health Statistical Year Book 2015. Saudi Ministry of Health.p.28-49. Available from: http://www.moh.gov.sa/ministry/statistics/book/pages/ default.aspx.

22. Alomi YA. National Primary Care Pharmacist Competency System at $\mathrm{MOH}$ in Saudi Arabia. J Pharm Pharma Sciences. 2017;1(14):1-5.

23. Alomi YA. Primary Care Center Pharmacy Manpower New Guidelines in Saudi Arabia. J Pharmacology Clinical Res. 2016;1(1).

24. Bond C, Raehl C, Franke T. Clinical Pharmacy Services, Pharmacist Staffing, and Drug Costs in United States Hospitals. Pharmacotherapy. 1999;19(12):1354-62.

25. Bond C, Raehl C, Franke T. Total Cost of Care, and Length of Stay in United States Pharmacy Services and Staffing. Pharmacotherapy. 2001;21(2):129-41.

26. Bond CA, Raehl CL. Clinical pharmacy services, pharmacy staffing, and hospital mortality rates. Pharmacotherapy. 2007;27(4):481-93.

27. Ministry of Health. A Achievements 2013. 1st Ed. Ministry of Health, Saudi Arabia. 2011.p.132-5.

28. Alomi YA. Patient satisfaction of pharmaceutical care system at Ministry of Health in Saudi Arabia. BAOJ Pharm Sci. 2016;2:19.

29. Bloom BS. Health manpower planning. Health Service Res. 1980;15(1):67-8.

Cite this article as: Alomi YA, Alhennawi K, Khayayt N. Pharmacy Workload And Workforce Requirements At Moh Primary Health Care Center During Ten Years Mass Gathering Hajj (2006-2015) In Makah Region, Saudi Arabia. J Pharm Pract Community Med. 2017;3(4s):S61-S66. 